\title{
Article \\ Definition of Outcome-Based Prostate-Specific Antigen (PSA) Thresholds for Advanced Prostate Cancer Risk Prediction
}

\author{
Simona Ferraro ${ }^{1}$ **, Marco Bussetti ${ }^{1}$, Niccolò Bassani ${ }^{2}$, Roberta Simona Rossi ${ }^{3}$, Giacomo Piero Incarbone ${ }^{4}$, \\ Filippo Bianchi ${ }^{3}$, Marco Maggioni ${ }^{5}$, Letterio Runza ${ }^{5}$, Ferruccio Ceriotti ${ }^{6}$ (D) and Mauro Panteghini ${ }^{1,7}$ (D)
}

check for

updates

Citation: Ferraro, S.; Bussetti, M.; Bassani, N.; Rossi, R.S.; Incarbone, G.P.; Bianchi, F.; Maggioni, M.; Runza, L.; Ceriotti, F.; Panteghini, M. Definition of Outcome-Based Prostate-Specific Antigen (PSA) Thresholds for Advanced Prostate Cancer Risk Prediction. Cancers 2021, 13, 3381. https://doi.org/10.3390/ cancers13143381

Academic Editors: Alfonso Urbanucci and Delila Gasi Tandefelt

Received: 3 May 2021

Accepted: 30 June 2021

Published: 6 July 2021

Publisher's Note: MDPI stays neutral with regard to jurisdictional claims in published maps and institutional affiliations.

Copyright: (c) 2021 by the authors. Licensee MDPI, Basel, Switzerland. This article is an open access article distributed under the terms and conditions of the Creative Commons Attribution (CC BY) license (https:/ / creativecommons.org/licenses/by/ $4.0 /)$.
1 Unità Operativa Patologia Clinica, ASST Fatebenefratelli-Sacco, Ospedale 'Luigi Sacco', Via GB Grassi 74, 20157 Milano, Italy; marco.bussetti@unimi.it (M.B.); mauro.panteghini@unimi.it (M.P.)

2 Statistical Consultant, Flat 5 Hazel Court Avenue, Hitchin SG4 9SJ, UK; niccolo.bassani@gmail.com

3 Unità Operativa Anatomia Patologica, ASST Fatebenefratelli-Sacco, Ospedale 'Luigi Sacco', Via GB Grassi 74, 20157 Milano, Italy; rossi.roberta@asst-fbf-sacco.it (R.S.R.); filippo.bianchi@asst-fbf-sacco.it (F.B.)

4 Urologia, ASST Fatebenefratelli-Sacco, Ospedale 'Luigi Sacco', Via GB Grassi 74, 20157 Milano, Italy; incarbone.giacomo@asst-fbf-sacco.it

5 Unità Operativa Anatomia Patologica, Fondazione IRCCS Ca' Granda Ospedale Maggiore Policlinico Via F. Sforza 35, 20122 Milano, Italy; marco.maggioni@policlinico.mi.it (M.M.); letterio.runza@policlinico.mi.it (L.R.)

6 Laboratorio Analisi, Fondazione IRCCS Ca' Granda Ospedale Maggiore Policlinico Via F. Sforza 35, 20122 Milano, Italy; ferruccio.ceriotti@policlinico.mi.it

7 Dipartimento di Scienze Biomediche e Cliniche 'Luigi Sacco', Università Degli Studi di Milano, 20157 Milano, Italy

* Correspondence: simona.ferraro@asst-fbf-sacco.it

Simple Summary: In this study, we used a well calibrated risk prediction model to define prostatespecific antigen (PSA) thresholds for identifying or excluding advanced prostate cancer (PCa) as an aid to personalize management of the diagnostic workup. PSA concentrations $\leq 4.1$ ( $<65$ years old) and $\leq 3.7 \mu \mathrm{g} / \mathrm{L}$ ( $\geq 65$ years old) excluded an advanced PCa in patients without glandular inflammation, while PSA $>5.7(<65)$ and $>6.1 \mu \mathrm{g} / \mathrm{L}(\geq 65)$ suggested a biopsy referral. In the presence of glandular inflammation, PSA does not provide a valid estimate for risk of advanced cancer since the marker variability is higher and the pre-test probability of PCa is low in this group. The proposed PSA thresholds may allow an individualized approach to the diagnostic workup, assisting patients in making an informed decision. However, patients with asymptomatic prostatitis cannot benefit from the use of this model since they cannot be pre-biopsy identified.

Abstract: We defined prostate-specific antigen (PSA) thresholds from a well calibrated risk prediction model for identifying and excluding advanced prostate cancer (PCa). We retrieved 902 biopsied patients with a pre-biopsy PSA determination (Roche assay). A logistic regression model predictive for PCa including the main effects [i.e., PSA, age, histological evidence of glandular inflammation (GI)] was built after testing the accuracy by calibration plots and Hosmer-Lemeshow test for goodness of fit. PSA thresholds were derived by assuming a diagnostic sensitivity of $95 \%$ (rule-out) and $80 \%$ (rule-in) for overall and advanced/poorly differentiated PCa. In patients without GI, serum PSA concentrations $\leq 4.1$ ( $<65$ years old) and $\leq 3.7 \mu \mathrm{g} / \mathrm{L}$ ( $\geq 65$ years old) excluded an advanced PCa (defined as Gleason score $\geq 7$ at biopsy), with a negative predictive value of $95.1 \%$ [95\% confidence interval (CI): 83.0-98.7] and 88.8\% (CI: 80.2-93.9), respectively, while PSA > $5.7(<65)$ and $>6.1 \mu \mathrm{g} / \mathrm{L}$ $(\geq 65)$ should address biopsy referral. In presence of GI, PSA did not provide a valid estimate for risk of advanced cancer because of its higher variability and the low pre-test probability of PCa. The proposed PSA thresholds may support biopsy decision except for patients with asymptomatic prostatitis who cannot be pre-biopsy identified.

Keywords: calibration; risk prediction; prostate cancer; immunoassay; inflammation 


\section{Introduction}

Recently released clinical practice guidelines (CPGs) no longer recommend decision thresholds of prostate-specific antigen (PSA) for the early detection of prostate cancer (PCa) to rule in patients for prostate biopsy referral [1-3]. Rather the expert panels have endorsed the stratification of PCa risk according to individual PSA values and age, aiming to offer biopsy to patients at increased risk of high-grade disease, to promote active surveillance of slow-growing $\mathrm{PCa}$, and to run effective longitudinal PSA retesting programs $[1,4]$. Accordingly, CPGs try to adapt the time of repetition of PSA testing to the estimated individual risk, with the result of heterogeneous recommendations [1]. For instance, the American Cancer Society indicated a yearly PSA retesting for all patients with a value $\geq 2.5 \mu \mathrm{g} / \mathrm{L}$ at baseline, whereas other CPGs lowered the threshold to $1.0 \mu \mathrm{g} / \mathrm{L}$, restricted the monitoring to men aged 55-69 years, and/or extended the time interval for PSA rescreening to $2-4$ years [1-3,5].

The main challenge remains to use PSA results to identify patients for prostate biopsy referral who most likely will benefit from an intervention defined by a shared decision made between the patients and the care provider $[4,6]$. A wide spectrum of pre-biopsy risk nomograms has been proposed as an aid in decision with the aim to maximize the diagnostic specificity, but the overall poor predictive capability resulting from the validation phases has conditioned the recommendation of their use [7-9]. On the other hand, several methodological issues have been identified within studies developing pre-biopsy risk models, such as low numbers of biopsy core that were examined, presence of verification bias in studies including men from screening programs, lack of calibration of predictive models, and/or use of different PSA assays as an additional cause of miscalibration and source of intra-study heterogeneity [1,9-12]. Some experts have asked how much accurate the estimate of the risk predicted at the individual level is, underlining the burden of unnecessary biopsies and the rate of missed aggressive cancer [13]. These drawbacks stress the use of a more rigorous research methodology, as well as the need to tune risk models to the current clinical goals in order to pragmatically fulfill the redesigned screening strategies. In other words, the predicted risk should inform an individual on the probability to exclude or detect an aggressive $\mathrm{PCa}$, with an acceptable accuracy of recommending biopsy referral.

There is an unmet need for the use of PSA testing to prevent overdiagnosis, overtreatment, and unnecessary invasive procedures. The clinical goals for the use of PSA test in decision making should be better defined. Studies in literature which have evaluated the performance of the risk models, recommended values for diagnostic sensitivity ranging between $90 \%$ and $95 \%$, while the ratio of one cancer detected for every three performed biopsies [corresponding to a positive predictive value (PPV) of 33.3\%] was considered acceptable $[9,14]$. On the other hand, the estimate and the reliability of predictive values are strongly dependent on the rate of PCa incidence in the referral population $[15,16]$, so that epidemiological data should be kept in mind to ultimately transfer affordable risk thresholds into the clinical practice. Available data indicate a 1:4 ratio between the annual incidence of PCa in men aged 50-64 years vs. the 65-over 85 years group, with an exponential growth between 50 and 64 years and a plateau after 65 years [17]. Furthermore, to exploit the full potential of PSA-based risk models for biopsy referral, the outcome should shift from the detection of PCa of any grade to advanced grade PCa only, given the low lethality and the questionable benefit of treating men with low-grade cancer $[4,6,13]$. By considering the highlighted issues, in this study we defined PSA thresholds using a well calibrated risk prediction model for identifying or excluding advanced $\mathrm{PCa}$, as an aid in personalized management of the diagnostic workup of redesigned screening programs.

\section{Results}

\subsection{Characteristics of Studied Patients}

The main features of the studied case series are reported in Table 1. Out of 902 patients, $415(46.0 \%)$ had PCa. Patients with PCa were older and had higher PSA values than those without the disease. Both age and serum PSA concentrations were significantly increased in 
advanced stages of $\mathrm{PCa}$, with $\sim 80 \%$ of patients with advanced/poorly differentiated disease aged over 65 years. Although the distribution of age was symmetrical (mean, 67.9 years), the distribution of PSA values was skewed with a heavy tail on the right end. Accordingly, PSA concentrations followed natural logarithmic transformation (ln) to generate a nearnormal distribution. Figure 1 and Figure S1 in the online Data Supplement display the distributions of age and ln PSA in patients with and without PCa, and with or without histological evidence of glandular inflammation, respectively. The presence of glandular inflammation markedly prevailed in patients free of cancer vs. those diagnosed with PCa $(41.7 \%$ vs. $8.2 \%, p<0.001)$, and far lower in advanced $(4.9 \%)$ and poorly differentiated PCa (1.6\%). In cancer-free patients, the presence of inflammation significantly increased PSA concentrations [6.64 $\mu \mathrm{g} / \mathrm{L}(4.6-11.1)$ vs. $5.2 \mu \mathrm{g} / \mathrm{L}(3.7-7.3) ; p<0.0001]$.

Table 1. Main characteristics of the studied case series.

\begin{tabular}{|c|c|c|c|c|}
\hline Patients & Age, Years ${ }^{a}$ & No. $\geq 65$ Years Old & PSA, $\mu \mathrm{g} / \mathrm{L}^{\mathrm{a}}$ & $\begin{array}{l}\text { Patients with } \\
\text { Histological Evidence } \\
\text { of Glandular } \\
\text { Inflammation }\end{array}$ \\
\hline Overall $(\mathrm{n}=902)$ & $69(62-74)$ & $594(65.9 \%)$ & $6.1(4.5-9.9)$ & $237(26.3 \%)$ \\
\hline Non PCa $(\mathrm{n}=487 ; 54.0 \%)$ & $66(60-73)$ & $278(57.1 \%)$ & $5.6(4.1-8.2)$ & $203(41.7 \%)$ \\
\hline $\mathrm{PCa}(\mathrm{n}=415 ; 46.0 \%)$ & $71(65-76)^{b}$ & $316(76.1 \%)$ & $7.3(5.1-12.3)^{b}$ & $34(8.2 \%)$ \\
\hline $\begin{array}{l}\text { PCa with Gleason score }<7 \\
\qquad(\mathrm{n}=168 ; 40.5 \%)\end{array}$ & $70(63-74)$ & $118(70.2 \%)$ & $5.6(4.2-7.4)$ & $22(13.1 \%)$ \\
\hline $\begin{array}{l}\text { PCa with Gleason score } \geq 7 \\
(\mathrm{n}=247 ; 59.5 \%)\end{array}$ & $71(66-77)^{c}$ & $197(79.8 \%)$ & $9.8(6.1-23.4)^{\mathrm{c}}$ & $12(4.9 \%)$ \\
\hline $\begin{array}{c}\text { PCa with ISUP } \\
\text { grade }<3(\mathrm{n}=231 ; 55.7 \%)\end{array}$ & $70(63-75)$ & $164(71.0 \%)$ & $5.8(4.4-8.2)$ & $31(13.4 \%)$ \\
\hline $\begin{array}{l}\text { PCa with ISUP grade } \geq 3 \\
\quad(\mathrm{n}=184 ; 44.3 \%)\end{array}$ & $72(67-77)^{d}$ & $151(82.1 \%)$ & $11.6(7.1-33.6)^{d}$ & $3(1.6 \%)$ \\
\hline
\end{tabular}

PCa, prostatic carcinoma; ISUP, International Society of Urological Pathology. ${ }^{a}$ Median and interquartile range. ${ }^{\mathrm{b}} p<0.001 \mathrm{vs.}$ non PCa. ${ }^{\mathrm{c}} p<0.001$ vs. Gleason score $<7 .{ }^{\mathrm{d}} p<0.001$ vs. ISUP $<3$.
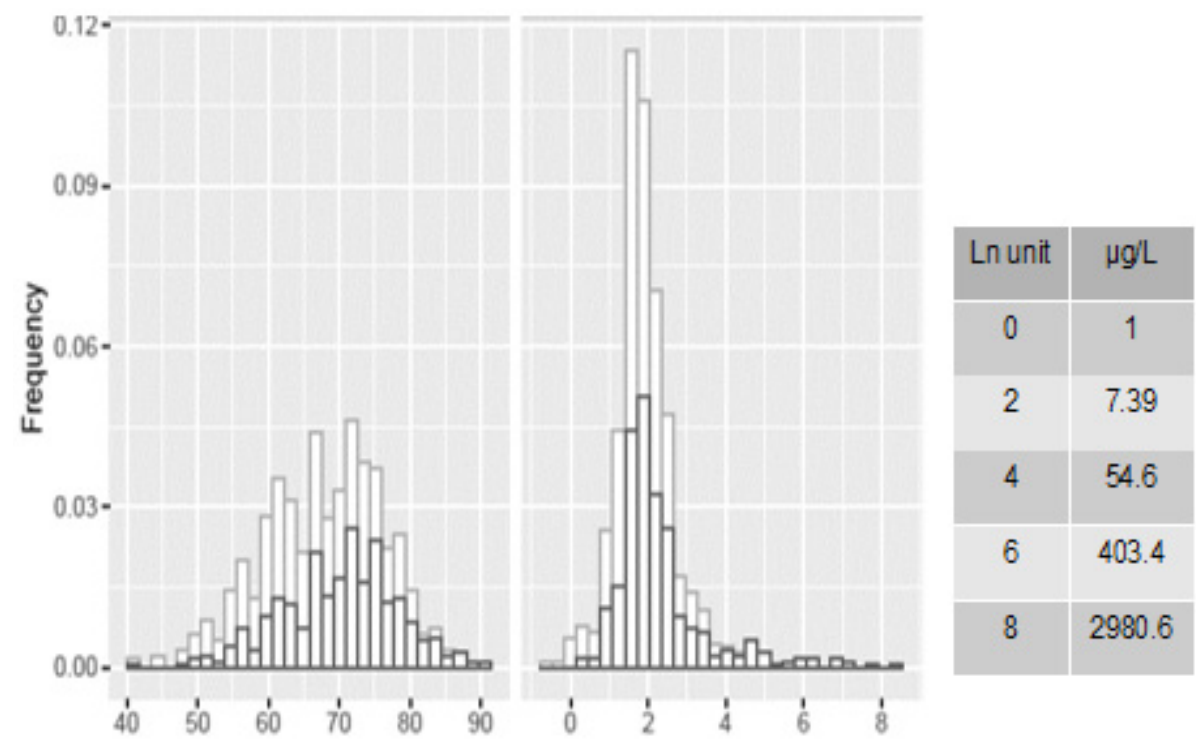

Figure 1. Distribution of age (left) and ln PSA concentrations (right) in patients with (black histograms) and without (grey histograms) prostatic cancer. 


\subsection{Predictive Models}

Logistic regression models predictive for PCa which showed the best goodness of fit (Akaike information criterion, AIC $=977.1$ ) and predictive ability (area under the ROC curve, $\mathrm{AUC}=0.79$, CI: 0.76-0.82) included the main effects, i.e., PSA on In scale, age, histological evidence of glandular inflammation, as covariates, and the PSA by age interaction. Calibration plots on overall case series using as outcome the diagnosis of PCa of any grade, Gleason score $\geq 7$ and ISUP grade $\geq 3 \mathrm{PCa}$ did not show a systematic pattern of over- or underestimation (Figure S2). However, some fluctuations around the diagonal line occurred, in particular for fitted predicted probability values $<0.4$ with Gleason score $\geq 7$ and ISUP grade $\geq 3$ PCa outcomes, and $<0.8$ with PCa of any grade as outcome. Therefore, the Hosmer-Lemeshow goodness of fit test was considered using four groups to split the predicted probabilities [number of groups $=$ number of covariates $(p=3)+1$ ]. The test produced non-significant $p$ values for all models ( 0.06 for any grade tumors, 0.78 for Gleason score $\geq 7$, and 0.85 for ISUP grade $\geq 3 \mathrm{PCa}$, respectively), suggesting there be no difference between predicted and observed probabilities. By considering subgroups partitioned according to the age threshold of 65 years, well calibrated models were observed in patients without evidence of glandular inflammation (Figures S3 and S4).

Derived logistic regression equations estimated that an absolute PSA increase of $1 \mathrm{ln}$ unit (corresponding to $2.72 \mu \mathrm{g} / \mathrm{L}$ ) implied an age-adjusted odds ratio (OR) of 2.72 (CI: 2.17-3.49), 5.3 (CI: 3.95-7.51), and 7.00 (CI: 4.93-10.54) in harboring any grade, advanced, and poorly differentiated $\mathrm{PCa}$, respectively. Table 2 shows the individual probabilities [estimated according to the formula: $1 /\left(1+e^{-\log \text { odds }}\right)$ [18]] of harboring a PCa of any grade and of aggressive grade by assuming a PSA of $4.0 \mu \mathrm{g} / \mathrm{L}$.

Table 2. Simulation of the probability of harboring a prostatic cancer (PCa) of any grade, advanced (Gleason score $\geq 7$ ), and poorly differentiated grade (ISUP $\geq 3$ ) for an individual with a baseline PSA value of $4.0 \mu \mathrm{g} / \mathrm{L}$.

\begin{tabular}{|c|c|c|c|c|}
\hline Outcome & Equation $^{\text {a }}$ & $\begin{array}{l}\text { Histological Evidence of } \\
\text { Glandular Inflammation }\end{array}$ & Age, Years & $\begin{array}{c}\text { Individual Probability } \\
\mathrm{b}(95 \% \mathrm{CI})\end{array}$ \\
\hline \multirow{2}{*}{ PCa of any grade } & \multirow{2}{*}{$\begin{array}{c}\text { Log odds }=-2.1+\ln (\mathrm{PSA})+ \\
0.80 \text { age }(\geq 65 \text { years })-2.50 \\
\text { inflammation (yes) }\end{array}$} & No & $\begin{array}{l}<65 \\
\geq 65\end{array}$ & $\begin{array}{l}33.5 \%(27.4-40.3) \\
53.0 \%(47.3-58.3)\end{array}$ \\
\hline & & Yes & $\begin{array}{l}<65 \\
\geq 65\end{array}$ & $\begin{array}{c}3.9 \%(2.3-6.3) \\
8.4 \%(5.2-12.4)\end{array}$ \\
\hline \multirow{2}{*}{ Gleason score $\geq 7$} & \multirow{2}{*}{$\begin{array}{l}\text { Log odds }=-4.5+1.68 \ln (\text { PSA }) \\
+0.83 \text { age }(\geq 65 \text { years })-3.32 \\
\text { inflammation }(\text { yes })\end{array}$} & No & $\begin{array}{l}<65 \\
\geq 65\end{array}$ & $\begin{array}{c}10.2 \%(7.1-14.7) \\
19.5 \%(16.5-25.9)\end{array}$ \\
\hline & & Yes & $\begin{array}{l}<65 \\
\geq 65\end{array}$ & $\begin{array}{l}0.4 \%(0.2-1.0) \\
0.9 \%(0.4-2.1)\end{array}$ \\
\hline \multirow{2}{*}{ ISUP grade $\geq 3$} & \multirow{2}{*}{$\begin{array}{c}\text { Log odds }=-5.7+1.96 \ln (\text { PSA }) \\
+0.97 \text { age }(\geq 65 \text { years })-4.91 \\
\text { inflammation (yes) }\end{array}$} & No & $\begin{array}{l}<65 \\
\geq 65\end{array}$ & $\begin{array}{c}4.9 \%(2.9-7.9) \\
11.9 \%(8.6-15.9)\end{array}$ \\
\hline & & Yes & $\begin{array}{l}<65 \\
\geq 65\end{array}$ & $\begin{array}{c}0.04 \%(0.008-0.2) \\
0.1 \%(0.02-0.5)\end{array}$ \\
\hline
\end{tabular}

${ }^{\mathrm{a}} p<0.000001$ for all coefficients in the equations. ${ }^{\mathrm{b}}$ Estimated according to the formula: $1 /\left(1+e^{-\log \text { odds }}\right)$.

\subsection{PSA Thresholds for Decision Making}

The fitted probabilities of overall and advanced PCa (according to Gleason and ISUP grading) vs. PSA values (ln scale), partitioned according to age threshold of 65 years and possible presence of glandular inflammation were visually inspected (Figures S5 and S6). In patients with histological evidence of glandular inflammation, the low PCa prevalence was a major drawback in the definition of PSA risk thresholds for advanced cancer and biopsy referral. Our data only provide the possibility to make some inference on the ability of PSA testing to exclude PCa in patients $\geq 65$ years old with evidence of glandular inflammation: in this subgroup, a PSA value $<8.3 \mu \mathrm{g} / \mathrm{L}$ ruled out the presence of PCa of any grade with a negative predictive value (NPV) of $98.6 \%$ (CI: 90.8-99.8). 
Considering the 381 PCa patients without histological evidence of glandular inflammation, we were able to estimate for each partition, by setting the diagnostic sensitivity at $95 \%$ (rule out) and $80 \%$ (rule in), the corresponding PSA thresholds, together with the estimated sensitivity, specificity, and predictive values (Table 3). In patients $<65$ years old, a PSA value $>5.7 \mu \mathrm{g} / \mathrm{L}$ was associated to a PPV of $35.9 \%$, corresponding to approximately one advanced cancer detected every three performed biopsies. PSA values $\leq 4.1 \mu \mathrm{g} / \mathrm{L}$ and $\leq 4.9 \mu \mathrm{g} / \mathrm{L}$ ruled out advanced (Gleason score $\geq 7$ ) and poorly differentiated (ISUP grade $\geq 3$ ) PCa, with a NPV of $95.1 \%$ and $97.5 \%$, respectively. In patients $\geq 65$ years old, PSA threshold values of $>5.3 \mu \mathrm{g} / \mathrm{L}$ (Gleason score $\geq 7$ ) and $>6.1 \mu \mathrm{g} / \mathrm{L}$ (ISUP grade $\geq 3$ ) can be adopted for biopsy referral, giving a PPV slightly higher than 50\%, indicating a rate of $\sim 1: 2$ between detected cancers and performed biopsies. On the other hand, PSA results $<3.7 \mu \mathrm{g} / \mathrm{L}$ excluded the presence of an advanced PCa, with a NPV of $88.8 \%$.

Table 3. PSA risk thresholds and estimated diagnostic parameters derived by assuming sensitivities of $95 \%$ and $80 \%$ for overall and advanced/poorly differentiated prostatic cancer (PCa) by considering only patients without histological evidence of glandular inflammation.

\begin{tabular}{|c|c|c|c|c|c|c|c|}
\hline Age Group & Outcome $^{a}$ & $\begin{array}{l}\text { Imposed } \\
\text { Sensitivity }\end{array}$ & $\begin{array}{c}\text { PSA Threshold, } \\
\mu \mathrm{g} / \mathrm{L}\end{array}$ & $\begin{array}{c}\text { Sensitivity, } \\
\%\end{array}$ & $\begin{array}{c}\text { Specificity, } \\
\%\end{array}$ & PPV, \% & NPV, \% \\
\hline \multirow{6}{*}{$<65$ years } & \multirow{2}{*}{$\begin{array}{c}\text { PCa of any } \\
\text { grade }(43.5 \%)\end{array}$} & $95 \%$ & 2.8 & $\begin{array}{c}94.6 \\
(87.9-98.2)\end{array}$ & $6.6(2.9-12.6)$ & $\begin{array}{c}43.8 \\
(42.1-45.5)\end{array}$ & $\begin{array}{c}61.5 \\
(35.1-82.6)\end{array}$ \\
\hline & & $80 \%$ & 4.2 & $\begin{array}{c}79.6 \\
(69.9-87.2)\end{array}$ & $\begin{array}{c}26.4 \\
(18.8-35.2)\end{array}$ & $\begin{array}{c}45.4 \\
(41.8-49.1)\end{array}$ & $\begin{array}{c}62.7 \\
(50.6-73.5)\end{array}$ \\
\hline & \multirow{2}{*}{$\begin{array}{c}\text { Gleason } \\
\text { score } \\
\geq 7(21.5 \%)\end{array}$} & $95 \%$ & 4.1 & $\begin{array}{c}95.7 \\
(85.2-99.5)\end{array}$ & $\begin{array}{c}23.2 \\
(17.1-30.3)\end{array}$ & $\begin{array}{c}25.4 \\
(23.5-27.4)\end{array}$ & $\begin{array}{c}95.1 \\
(83.0-98.7)\end{array}$ \\
\hline & & $80 \%$ & 5.7 & $\begin{array}{c}80.4 \\
(66.1-90.6)\end{array}$ & $\begin{array}{c}60.7 \\
(52.9-68.1) \\
\end{array}$ & $\begin{array}{c}35.9 \\
(30.7-41.5)\end{array}$ & $\begin{array}{c}91.9 \\
(86.2-95.4)\end{array}$ \\
\hline & \multirow{2}{*}{$\begin{array}{l}\text { ISUP grade } \\
\geq 3(14.9 \%)\end{array}$} & $95 \%$ & 4.9 & $\begin{array}{c}93.8 \\
(79.2-99.2)\end{array}$ & $\begin{array}{c}42.3 \\
(35.0-49.8)\end{array}$ & $\begin{array}{c}22.2 \\
(19.7-25.0)\end{array}$ & $\begin{array}{c}97.5 \\
(90.9-99.3)\end{array}$ \\
\hline & & $80 \%$ & 5.9 & $\begin{array}{c}81.3 \\
(63.6-92.8)\end{array}$ & $\begin{array}{c}63.7 \\
(56.3-70.7)\end{array}$ & $\begin{array}{c}28.3 \\
(23.4-33.7)\end{array}$ & $\begin{array}{c}95.1 \\
(90.3-97.6)\end{array}$ \\
\hline \multirow{6}{*}{$\geq 65$ years } & \multirow{2}{*}{$\begin{array}{c}\text { PCa of any } \\
\text { grade }(63.9 \%)\end{array}$} & $95 \%$ & 2.5 & $\begin{array}{c}94.8 \\
(91.6-97.1)\end{array}$ & $\begin{array}{c}17.2 \\
(11.7-23.9)\end{array}$ & $\begin{array}{c}66.9 \\
(65.2-68.6)\end{array}$ & $\begin{array}{c}65.1 \\
(50.7-77.2)\end{array}$ \\
\hline & & $80 \%$ & 4.7 & $\begin{array}{c}79.9 \\
(74.8-84.3)\end{array}$ & $\begin{array}{c}40.5 \\
(32.9-48.4)\end{array}$ & $\begin{array}{c}70.3 \\
(67.4-73.2)\end{array}$ & $\begin{array}{c}53.2 \\
(45.8-60.5)\end{array}$ \\
\hline & \multirow{2}{*}{$\begin{array}{c}\text { Gleason } \\
\text { score } \\
\geq 7(41.5 \%)\end{array}$} & $95 \%$ & 3.7 & $\begin{array}{c}95.2 \\
(91.1-97.8)\end{array}$ & $\begin{array}{c}26.9 \\
(21.6-32.7)\end{array}$ & $\begin{array}{c}48.0 \\
(46.0-50.0)\end{array}$ & $\begin{array}{c}88.8 \\
(80.2-93.9)\end{array}$ \\
\hline & & $80 \%$ & 5.3 & $\begin{array}{c}80.2 \\
(73.8-85.7)\end{array}$ & $\begin{array}{c}51.1 \\
(44.9-57.3)\end{array}$ & $\begin{array}{c}53.8 \\
(50.2-57.3)\end{array}$ & $\begin{array}{c}78.5 \\
(72.8-83.3)\end{array}$ \\
\hline & \multirow{2}{*}{$\begin{array}{l}\text { ISUP grade } \\
\geq 3(32.8 \%)\end{array}$} & $95 \%$ & 3.8 & $\begin{array}{c}95.3 \\
(90.5-98.1)\end{array}$ & $\begin{array}{c}25.1 \\
(20.3-30.4)\end{array}$ & $\begin{array}{c}38.3 \\
(36.6-40.1)\end{array}$ & $\begin{array}{c}91.6 \\
(83.7-95.8)\end{array}$ \\
\hline & & $80 \%$ & 6.1 & $\begin{array}{c}79.7 \\
(72.3-85.9)\end{array}$ & $\begin{array}{c}64.7 \\
(59.0-70.1)\end{array}$ & $\begin{array}{c}52.4 \\
(48.1-56.7)\end{array}$ & $\begin{array}{c}86.7 \\
(82.4-90.1)\end{array}$ \\
\hline
\end{tabular}

PPV, positive predictive value; NPV, negative predictive value. ${ }^{\text {a }}$ Prevalence in parentheses.

\subsection{Developing a PSA-Based Diagnostic Workup}

Figures 2 and 3 display the PSA-based diagnostic workup for patients aged $<65$ and $\geq 65$ years without evidence of prostate inflammation, determined based on the evidence obtained in our study, and including some additional second level tests, whose diagnostic performance aiding to refine the individual risk was demonstrated by the literature [19-23]. 


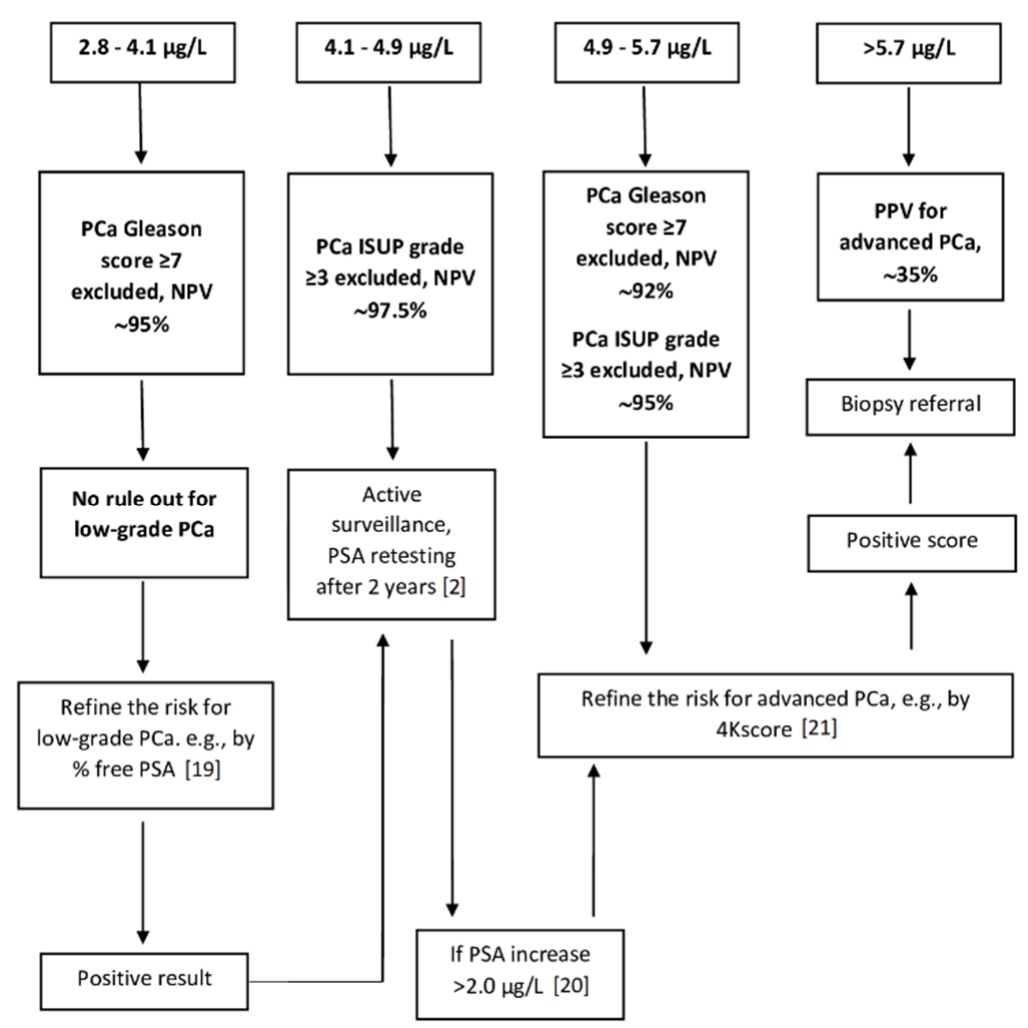

Figure 2. PSA - based diagnostic workup for patients $<65$ years old, with no evidence of glandular inflammation on histology. This workflow includes recommendations on second level approaches inferred from the available literature (references reported in parentheses). The above values represent pre-biopsy serum PSA concentrations. In black, information derived by this study. Note: Recommended active surveillance implies PSA retesting after two years and it is stopped if the risk of advanced cancer increases according to an absolute PSA increase over $2 \mu \mathrm{g} / \mathrm{L}$. It is reasonable to endorse the PSA retesting interval recommended by the American Urological Association [2]. PCa, prostatic cancer; NPV, negative predictive value; ISUP, International Society of Urological Pathology; PPV, positive predictive value; 4Kscore, 4-kallikrein panel score. 


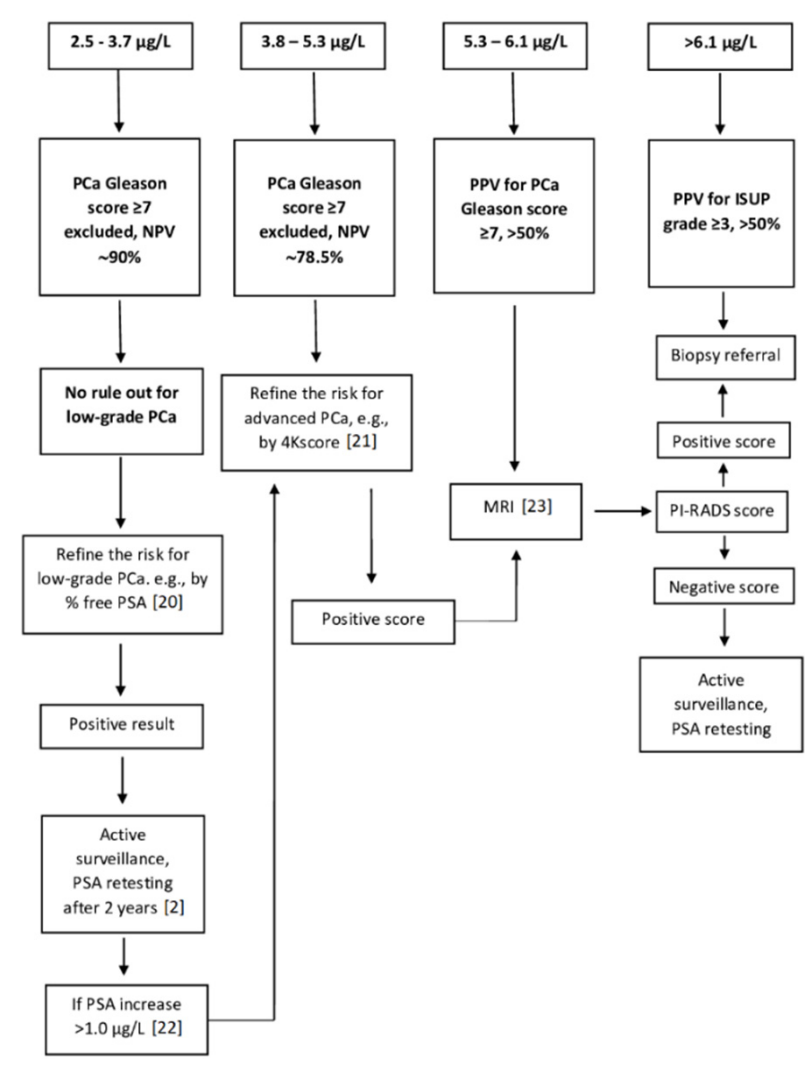

Figure 3. PSA — based diagnostic workup for patients $\geq 65$ years old, asymptomatic for glandular inflammation, including recommendations on second level approaches inferred from the available literature (references reported in parentheses). The above values represent pre-biopsy serum PSA concentrations. In black, information derived by this study. Note: Recommended active surveillance implies PSA retesting after two years and it is stopped if the risk of advanced cancer increases according to an absolute PSA increase over $1 \mu \mathrm{g} / \mathrm{L}$. It is reasonable to endorse the PSA retesting interval recommended by the American Urological Association [2]. PCa, prostatic cancer; NPV, negative predictive value; ISUP, International Society of Urological Pathology; PPV, positive predictive value; 4Kscore, 4-kallikrein panel score; MRI, multiparametric magnetic resonance imaging; PD-RAS, Prostate Imaging-Reporting and Data System.

\section{Discussion}

Current CPGs for early detection of PCa advise for a more selective use of PSA testing in the context of "shared decision-making", and promote individualized risk-adapted approaches to screening, biopsy referral, and treatment [1,4]. It is currently recommended to estimate the individual PSA-based odds of PCa to address the rescreening interval, active surveillance, and biopsy referral, seeking for a reduction of harms associated with the procedure invasiveness, overdiagnosis, and overtreatment of low-risk disease. Several meta-analyses have reported the contribution of risk models to improve the discriminative capability of PSA for PCa [7-9], and authoritative voices have claimed that the risk-benefit ratio is enhanced when the estimate of individual risk is unbiased and precise, the rule in capability to detect advanced stages is high, and there is a considerable decrease of undue biopsies $[13,24]$. To shift the harm-benefit balance, risk models should: (a) theoretically include variables easy to collect without requiring further expensive/invasive tests (e.g., assessment of prostate volume), (b) be well calibrated, showing a good agreement between the individual patient's estimated risk and the true risks, and (c) consider PSA thresholds in relation to a specific age range, since the predictive ability differs across age groups [13,25-27]. Our well calibrated model shows that PSA concentrations, histological evidence of prostatic inflammation and older age independently contributed to the estimation of the individual risk. 
It should be noted that in the majority of cases the histological presence of glandular inflammation confirms the clinical diagnosis of symptomatic prostatitis, the latter having higher prevalence with respect to the asymptomatic inflammation in patients over 60 years of age $[28,29]$. Histology contributes to the definition of an (asymptomatic) prostatitis in only $\sim 30 \%$ of biopsies performed in a screened population and more rarely $(18 \%$ of diagnoses) are associated with a PSA increase over $4.0 \mu \mathrm{g} / \mathrm{L}$ [29-32]. This is an important point to consider since the proposed risk model may generally run in a pre-biopsy setting as an aid to recommend biopsy referral if symptomatic prostatitis is excluded, but also may aid in the post-biopsy setting when histology shows an asymptomatic inflammation to prevent further investigations.

Age partitioning according to a single threshold of 65 years permits a well-powered evaluation in the subgroups, with an overall sample size and PCa prevalence in agreement with other large pre-biopsy cohorts [8]. This also takes into consideration that the ratio between the number of PCa cases and variables included in the model should not be $<10: 1$ [33]. This age threshold is supported by the evidence that the bulk of data on prebiopsy cohorts is retrieved from men with average ages falling in the 61-70 years range and that the current life expectancy in Western countries is $\sim 22$ years for 65-year-old men [8]. Furthermore, epidemiological data indicates that the risk of PCa follows an exponential trend after 50 years of age (113 cases/100,000/year in the range of 50-54 years vs. $495 / 100,000 /$ year in the range of 60-64 years, respectively), reaching a plateau in individuals over 65 years [17].

Some interesting information can be derived from our study. First, we confirmed that, even in patients $<65$ years old, the selection of a PSA threshold of $4.0 \mu \mathrm{g} / \mathrm{L}$ for biopsy referral implies an unfavorable risk-benefit ratio, leading to an overdiagnosis of low-grade tumors (individual probability of advanced PCa $\sim 10 \%$ ) [34]. In this group of patients, the poor cost-benefit ratio of PSA (re)screening for men with PSA values $<4.0 \mu \mathrm{g} / \mathrm{L}$ is conditioned by the very low risk of advanced $\mathrm{PCa}$ in this range of values and by the amount of PSA increase needed to significantly influence the ratio at the individual level, with a progression towards advanced clinical stages or a change in tumor grade assignment. Our evidence is aligned with other research data reporting that only $\leq 20 \%$ of men undergoing screening with PSA in the range $2.6-4.0 \mu \mathrm{g} / \mathrm{L}$ harbored a Gleason score $\geq 7$ PCa $[14,19,35]$. On the other hand, the evidence suggests that rescreening men aged $<65$ years with PSA at baseline $>4.0 \mu \mathrm{g} / \mathrm{L}$ for active surveillance of low-grade disease may have a favorable risk-benefit balance if performed biennially [2], in particular considering: (a) the slow growth of PCa of any histological grade, and (b) the reference change value of $\sim 20 \%$ useful to identify intraindividual PSA changes overtime significantly turning into clinically relevance $[25,36,37]$. Taking that into account, in our study, PSA values between 4.1 and $4.9 \mu \mathrm{g} / \mathrm{L}$ consistently excluded aggressive PCa (NPV, 97.5\%), therefore suggesting to place these patients under active surveillance with a biennial PSA retesting (Figure 2). A PSA increase $>2.0 \mu \mathrm{g} / \mathrm{L}$ for baseline concentrations $>4.0 \mu \mathrm{g} / \mathrm{L}$ may significantly enhance the identification of aggressive PCa [20,38]. In patients with PSA values between 4.9 and $5.7 \mu \mathrm{g} / \mathrm{L}$, in which the PSA rule-out power for advanced PCa is decreasing, a second level test, such as the 4-kallikrein panel score (4Kscore), may aid in the identification of advanced cancer risk, assuring a PPV $>95 \%$ [21]. Finally, it sounds reasonable in this population with a long-life expectancy to consider the PSA level $>5.7 \mu \mathrm{g} / \mathrm{L}$ for biopsy referral, since that at this marker concentration the ratio of one advanced cancer detected every 3 biopsies performed is fulfilled.

In patients $\geq 65$ years old, the rule-out power of PSA for advanced PCa, even in absence of glandular inflammation, is significantly reduced and the estimate of free PSA percentage may help to increase the NPV in patients with PSA concentrations $\leq 3.7 \mu \mathrm{g} / \mathrm{L}$ [19]. It is noteworthy that the predictive power of PSA testing in men $>62$ years with a baseline PSA $\leq 4.0 \mu \mathrm{g} / \mathrm{L}$ changes slowly across subsequent rescreening rounds, being associated to an average OR of only 2.1 for advanced PCa, when the value increased of $1.0 \mu \mathrm{g} / \mathrm{L}$ [22]. For patients with higher PSA values, the use of a second level test, such as the 4 Kscore, 
able to increase the PPV and the addition of multiparametric magnetic resonance imaging may refine the risk for advanced cancer and optimize biopsy referral (Figure 2) [21,23,39]. In patients with PSA values $>6.1 \mu \mathrm{g} / \mathrm{L}$, biopsy referral should be recommended.

It should be clarified that in the proposed diagnostic workup we recommend the use of second level investigations, such as free PSA percentage or 4Kscore, for patients falling within defined PSA ranges just considering their predictive contribution added to the baseline PSA values [19,21]. Notably, the use of 4 Kscore is conditioned by the difficult availability of the test; alternatively, the prostate health index may be considered in those laboratories measuring PSA by Beckman Coulter assay [21].

In our study, we were unable to define PSA risk thresholds for advanced cancer and biopsy referral in patients displaying glandular inflammation. This was due to the known low prevalence of PCa in this subgroup of patients and to the variable effect of the inflammatory status on the increase of PSA concentrations in serum $[21,32,36]$. This could not be circumvented by collapsing these partitions, since ROC curves built on the full model may consequently deviate from the monotonic function. In this situation, similar PSA results might be erroneously associated with significantly different predictive values. This risk is increased for biomarkers like PSA characterized by high inter-individual biological variability, which conditions per se the reliability of cut-off values [40]. The setup of risk prediction models on such pre-biopsy cohorts, although excluding the verification bias, may provide an overestimation of PSA predictive ability. In clinical practice, we may overcome this issue regarding whether the risk algorithm is addressed to patients with a considerable pre-test probability, according to the presence at baseline of known risk factors (i.e., ethnicity, family history, older age, positive digital rectal examination, and transrectal ultrasonography prostate volume), which however we were unable to completely retrieve in our evaluated patients [1].

A major limitation of our study is represented by the difficulty to clinically define the presence of glandular inflammation, a significant confounder of PSA interpretation, in a pre-biopsy setting. The majority of patients with prostatitis are symptomatic and may be diagnosed even if symptoms, such as dysuria, may be nonspecific. However, asymptomatic prostatitis may be occasionally detected in patients undergoing biopsy [29]. Therefore, studies conducted to identify serum biomarkers that may help to detect prostatic inflammation by adding their measurements to PSA in a pre-biopsy setting are warranted. If prostatitis is suspected clinically, administration of an antibiotic therapy before PSA testing is recommended. Previous studies showed that antibiotics may help avoid biopsy in selected patients whose PSA elevation was likely due to prostatitis [41]. A further limitation may be that PSA elevation may enter in the clinical criteria for biopsy referral and an overestimation of its predictive value may be suspected. However, this type of bias is likely to occur when the index test enters in the clinical criteria for determining the diagnostic outcome and this is not the case here since the diagnosis of PCa was independent of PSA being based on histological criteria.

\section{Materials and Methods}

\subsection{Patients, Histological Diagnosis, and PSA Determination}

We retrospectively retrieved a continuous case series of 902 patients, tested for total PSA in two academic hospitals in Milan from 2014 to 2020, before performing a transrectal ultrasound guided prostate biopsy.

The criteria used to recommend biopsy were the presence of known risk factors (i.e., family history and older age) associated to dubious or positive digital rectal examination, and/or to an increased transrectal ultrasonography prostate volume, and/or to a free PSA $<20 \%$.

Patients with a previous biopsy or an established diagnosis of PCa were excluded. Disease status (i.e., evidence/no evidence of PCa and of prostatic inflammation) was determined histologically for all patients by prostate biopsy on $>12$ cores. Gleason score and the International Society of Urological Pathology (ISUP) grade were used for PCa 
grading, the latter being now recommended to fulfill the updated CPGs [42]. PCa with a Gleason score $\geq 7$ and an ISUP grade $\geq 3$ have been both associated to a worse prognosis, but ISUP grading allows to split the Gleason score 7 patterns, including the prognostically different $3+4$ and $4+3$ groups, in ISUP grade 2 and 3, respectively [43]. The group $3+4$ (ISUP grade 2) mostly includes well differentiated cancers, whereas the group $4+3$ (ISUP grade 3) mostly includes poorly differentiated cancers [43].

The presence of prostatic inflammation was based on histological criteria and defined by an evident, not random presence of a granulocytic infiltrate in the histologic sections [44]. The characterization of the inflammatory pattern contributes to the clinical diagnosis of prostatitis syndromes classified into four groups according to National Institute of Health $(\mathrm{NIH})$ criteria [29]. It has been reported that $90 \%$ of symptomatic patients have inflammatory chronic prostatitis/chronic pelvic pain syndrome, while the remaining having asymptomatic prostatitis are defined on the basis of the histological evidence of an inflammatory pattern in subjects undergoing biopsy because of an occasional PSA elevation [29]. In our case series, patients with histological evidence of glandular inflammation were however not partitioned according to NIH categories or dichotomized according to the presence/absence of symptoms.

PSA measurements were carried out using an electrochemiluminescence immunoassay marketed by Roche Diagnostics, whose characteristics have been previously described in detail [36]. PSA for patients enrolled until 2017 were assayed on a Cobas e601 platform, while in the last three years the newly released Cobas e801 analyzer was employed. Results from the two systems were nicely aligned [36]. The review board of our institution approved the study, carried out according to the Helsinki Declaration of 1975, as revised in 1996.

\subsection{Statistical Analysis}

The required sample size was estimated according to a simulation based on previously published data [36], by setting $\mu 1=6.7 \mu \mathrm{g} / \mathrm{L}$ and $\mu 2=5.5 \mu \mathrm{g} / \mathrm{L}$ as means of distribution of PSA values in patients with and without PCa in the referral population, a SD $\sigma=3.5 \mu \mathrm{g} / \mathrm{L}$, one-sided test option, $\alpha=0.05$, and a power of 0.80 [45]. By considering a maximum of 5 theoretical partitions of clinical interest, a final sample size of 800 patients may prompt to a well powered investigation, as also confirmed by the available evidence [15].

Data were reported as percentages for categorical variables and median with interquartile range for quantitative variables. Differences between variables in different categories were assessed by applying chi-squared test (categorical) and Mann-Whitney rank-sum test (quantitative). Logistic regression models predictive for PCa including the main effects (PSA value, age, evidence of inflammatory pattern at histology) were separately built and the one with the greatest goodness of fit [estimated by Akaike information criterion (AIC)] and the highest predictive ability [estimated by the area under the ROC curve (AUC)] was selected. The accuracy of the final model was assessed graphically by inspecting the calibration plots [using locally weighted scatterplot smoothing (LOWESS), with a span of 0.1] and formally by using the Hosmer-Lemeshow test for goodness of fit (splitting the predicted probabilities in four groups) $[8,13]$. Sensitivity, specificity, and predictive values associated with defined PSA risk thresholds were derived. 95\% confidence intervals (CI) for sensitivity and specificity were estimated by Clopper-Pearson exact method, while CI for predictive values were obtained using a Wald-type interval on a logit scale. Patient age was partitioned using the threshold of 65 years according to the actual prevalence of PCa [17]. All statistical analyses were performed using R software, version 3.6.3 ( $R$ Foundation for Statistical Computing, Vienna, Austria

\section{Conclusions}

In conclusion, the proposed PSA-based risk prediction approach may allow individualization of the diagnostic workup and balance the prediction of advanced PCa and biopsy referral between harms and benefits, thus permitting patients to make an informed 
decision. The greatest limitation remains the clinical difficulty to exclude the presence of asymptomatic prostatitis in a pre-biopsy setting, which however should rarely occur in patients with a significant PSA increase.

PSA is an inexpensive diagnostic tool, but it may actually trigger excessive costs by increasing the second-level tests workload and affect the individual harm-benefit balance if results are not appropriately managed [46,47]. We propose that future clinical trials should be designed prospectively to validate the proposed strategy. Furthermore, we are unaware if our PSA risk thresholds should be considered method-dependent or may be widely applied, given that the harmonization among marketed PSA measuring systems may necessitate further improvement [10].

Supplementary Materials: The following are available online at https://www.mdpi.com/article/ 10.3390/cancers13143381/s1, Figure S1: Distribution of age (left) and ln PSA concentrations (right) in patients patients with and without histological evidence of glandular inflammation, Figure S2: Calibration plots reporting the predicted probability of cancer of any grade (A), Gleason's score $\geq 7$ (B) and ISUP grade $\geq 3$ (C) cancers by considering the overall case series. The grey zone represents the variability of the predicted values around the bisector. The cases are reported as black points, Figure S3: Calibration plots reporting the predicted probability of cancer of any grade (A), Gleason's score $\geq 7$ (B) and ISUP grade $\geq 3$ (C) cancers by considering $<65$ years old patients with no histological evidence of glandular inflammation. The grey zone represents the variability of the predicted values around the bisector. The cases are reported as black points, Figure S4: Calibration plots reporting the predicted probability of cancer of any grade (A), Gleason's score $\geq 7$ (B) and ISUP grade $\geq 3$ (C) cancers by considering $\geq 65$ years old patients with no histological evidence of glandular inflammation. The grey zone represents the variability of the predicted values around the bisector. The cases are reported as black points, Figure S5: Fitted probabilities of prostatic cancer of any grade (A), with Gleason's score $\geq 7$ (B), and ISUP grade $\geq 3$ (C) vs. PSA values (ln scale units) in the subgroup of patients with no histological evidence of glandular inflammation, partitioned according to age threshold of 65 years. Horizontal lines represent the $95 \%$ sensitivity thresholds. Figure S6: Fitted probabilities of prostatic cancer of any grade (A), with Gleason's score $\geq 7$ (B), and ISUP grade $\geq 3(\mathrm{C})$ vs. PSA values (ln scale units) in the subgroup of patients with glandular inflammation, partitioned according to age threshold of 65 years. Horizontal lines represent the $95 \%$ sensitivity thresholds.

Author Contributions: Conceptualization, S.F., M.B.; software, M.B., R.S.R., N.B.; validation, S.F., M.B., G.P.I; investigation, S.F., M.B., R.S.R.; resources, F.B., F.C., M.M., L.R.; data curation, S.F., M.B., R.S.R., N.B.; writing—original draft preparation, S.F.; writing—review and editing, F.C., M.P.; supervision, F.C., M.P. All authors have read and agreed to the published version of the manuscript.

Funding: This research received no external funding.

Institutional Review Board Statement: The study was conducted according to the guidelines of the Declaration of Helsinki and approved by the Ethics Committee of ASST Fatebenefratelli-Sacco (protocol code n. 2020/ST/221).

Informed Consent Statement: Informed consent was obtained from the subjects involved in the study.

Data Availability Statement: The data presented in this study are available in the article or supplementary files.

Acknowledgments: The Authors thank English mother-tongue Alessandra Stefania Rizzuto and Mary Lou Wratten (with expertise in biomarkers) for their revision of the text. The authors acknowledge support from the University of Milan through the APC initiative.

Conflicts of Interest: The authors declare no conflict of interest. 


\begin{abstract}
Abbreviations
CPGs, clinical practice guidelines; PCa, prostatic cancer; PSA, prostate-specific antigen; PPV, positive predictive value; ISUP, International Society of Urological Pathology; AIC, Akaike information criterion; AUC, area under the ROC curve; LOWESS, locally weighted scatterplot smoothing; CI, 95\% confidence interval; OR, odds ratio; NPV, negative predictive value; 4Kscore, 4-kallikrein panel score.
\end{abstract}

\title{
References
}

1. Ferraro, S.; Bussetti, M.; Panteghini, M. Serum prostate-specific antigen testing for early detection of prostate cancer: Managing the gap between clinical and laboratory practice. Clin. Chem. 2021, 67, 602-609. [CrossRef] [PubMed]

2. Carter, H.B.; Albertsen, P.C.; Barry, M.J.; Etzioni, R.; Freedland, S.J.; Greeneet, K.L.; Holmberg, L.; Kantoff, P.; Konety, B.R.; Murad, M.H.; et al. Early detection of prostate cancer: AUA guideline. J. Urol. 2013, 190, 419-426. Available online: https: //www.auanet.org/guidelines/prostate-cancer-earlydetection-guideline (accessed on 29 April 2021). [CrossRef] [PubMed]

3. Gandaglia, G.; Albers, P.; Abrahamsson, P.-A.; Briganti, A.; Catto, J.W.; Chapple, C.R.; Montorsi, F.; Mottet, N.; Roobol, M.J.; Sønksen, J.; et al. Structured population-based prostate-specific antigen screening for prostate cancer: The European Association of Urology Position in 2019. Eur. Urol. 2019, 76, 142-150. [CrossRef] [PubMed]

4. Vickers, A.J. Redesigning prostate cancer screening strategies to reduce overdiagnosis. Clin. Chem. 2019, 65, 39-41. [CrossRef] [PubMed]

5. Wolf, A.M.D.; Wender, R.C.; Etzioni, R.B.; Thompson, I.M.; D’Amico, A.V.; Volk, R.J.; Brooks, D.D.; Dash, C.; Guessous, I.; Andrews, K.; et al. American Cancer Society PCa Advisory Committee. CA Cancer J. Clin. 2010, 60, 70-98. [CrossRef] [PubMed]

6. Carlsson, S.V.; Lilja, H. Perspective on prostate cancer screening. Clin. Chem. 2019, 65, 24-27. [CrossRef]

7. Schröder, F.; Kattan, M.W. The comparability of models for predicting the risk of a positive prostate biopsy with prostate-specific antigen alone: A systematic review. Eur. Urol. 2008, 54, 274-290. [CrossRef] [PubMed]

8. Louie, K.S.; Seigneurin, A.; Cathcart, P.; Sasieni, P. Do prostate cancer risk models improve the predictive accuracy of PSA screening? A meta-analysis. Ann. Oncol. 2015, 26, 848-864. [CrossRef]

9. Aladwani, M.; Lophatananon, A.; Ollier, W.; Muir, K. Prediction models for prostate cancer to be used in the primary care setting: A systematic review. BMJ Open 2020, 10, e034661. [CrossRef]

10. Ferraro, S.; Bussetti, M.; Rizzardi, S.; Braga, F.; Panteghini, M. Verification of harmonization of serum total and free prostatespecific antigen (PSA) measurements and implications for medical decisions. Clin. Chem. 2021, 67, 543-553. [CrossRef]

11. Stephan, C.; Klaas, M.; Muller, C.; Schnorr, D.; Loening, S.; Jung, K. Interchangeability of measurements of total anfree prostatespecific antigen in serum with 5 frequently used assay combinations: An update. Clin. Chem. 2006, 52, 59-64. [CrossRef] [PubMed]

12. Filella, X.; Albaladejo, M.D.; Allue', J.A.; Castano, M.A.; Morell-Garcia, D.; Ruiz, M.A.; Santamaria, M.; Torrejon, M.J.; Gimenez, N. Prostate cancer screening: Guidelines review and laboratory issues. Clin. Chem. Lab. Med. 2019, 57, 1474-1487. [CrossRef] [PubMed]

13. Carlsson, S.; Assel, M.; Vickers, A. Letter to the editor concerning 'Do prostate cancer risk models improve the predictive accuracy of PSA screening? A meta-analysis'. Ann. Oncol. 2015, 26, 1031. [CrossRef] [PubMed]

14. Haese, A.; Dworschack, R.T.; Partin, A.W. Percent free prostate-specific antigen in the total prostate-specific antigen 2 to $4 \mathrm{ng}$./ $\mathrm{mL}$ range does not substantially increase the number of biopsies needed to detect clinically significant prostate cancer compared to the 4 to $10 \mathrm{ng} . / \mathrm{mL}$. range. J. Urol. 2002, 168, 504-508. [CrossRef]

15. Vickers, A.J. Markers for the early detection of prostate cancer: Some principles for statistical reporting and interpretation. J. Clin. Oncol. 2014, 32, 4033-4034. [CrossRef]

16. Fiala, C.; Diamandis, E.P. A multi-cancer detection test: Focus on the positive predictive value. Ann. Oncol. 2020, 31, 1267-1268. [CrossRef]

17. Statistics Canada, Canadian Cancer Registry (CCR) Database (July 2011 File) (CANSIM Table 103-0550). Rates for ICD-O-3 Primary Sites of Cancer, by Sex, Canada, Provinces and Territories, Annual. Prostate Cancer, Incidence Rates Per 100,000, by Age Group, Canada. 2007. Available online: https://www150.statcan.gc.ca/n1/pub/82-624-x/2011001/article/chart/11596-09 -chart9-eng.htm (accessed on 29 April 2021).

18. Vickers, A.J. Prediction models in cancer care. CA Cancer J. Clin. 2011, 61, 315-326. [CrossRef] [PubMed]

19. Catalona, W.J.; Partin, A.W.; Finlay, J.A.; Chan, D.W.; Rittenhouse, H.G.; Wolfert, R.L.; Woodrum, D.L. Use of percentage of free prostate-specific antigen to identify men at high risk of prostate cancer when PSA-levels are 2.51-4 ng/mL and digital rectal examination is not suspicious for prostate cancer: An alternative model. Urology 1999, 54, 220-224. [CrossRef]

20. Thompson, I.M.; Ankerst, D.P. Prostate-specific antigen in the early detection of prostate cancer. CMAJ 2007, 176, 1853-1858. [CrossRef]

21. Russo, G.I.; Regis, F.; Castelli, T.; Favilla, V.; Privitera, S.; Giardina, R.; Cimino, S.; Morgia, G. A systematic review and metaanalysis of the diagnostic accuracy of prostate health index and 4-kallikrein panel score in predicting overall and high-grade prostate cancer. Clin. Genitourin Cancer 2017, 15, 429-439. [CrossRef] 
22. Thompson, I.M.; Pauler, D.K.; Goodman, P.J.; Tangen, C.M.; Lucia, M.S.; Parnes, H.L.; Minasian, L.M.; Ford, L.G.; Lippman, S.M.; Crawford, E.D.; et al. Prevalence of prostate cancer among men with a prostate-specific antigen level $<$ or $=4.0 \mathrm{ng}$ per milliliter. N. Engl. J. Med. 2004, 350, 2239-2246.

23. Olleik, G.; Kassouf, W.; Aprikian, A.; Hu, J.; Vanhuyse, M.; Cury, F.; Peacock, S.; Bonnevier, E.; Palenius, E.; Dragomir, A. Evaluation of new tests and interventions for prostate cancer management: A systematic review. J. Natl. Compr. Cancer Netw. 2018, 16, 1340-1351. [CrossRef] [PubMed]

24. Carlsson, S.V.; Roobol, M.J. What's new in screening in 2015? Curr. Opin. Urol. 2016, 26, 447-458. [CrossRef] [PubMed]

25. Vickers, A.J.; Ulmert, D.; Serio, A.M.; Björk, T.; Scardino, P.T.; Eastham, J.A.; Berglund, G.; Lilja, H. The predictive value of prostate cancer biomarkers depends on age and time to diagnosis: Towards a biologically-based screening strategy. Int. J. Cancer 2007, 121, 2212-2217. [CrossRef]

26. Carlsson, S.; Assel, M.; Sjoberg, D.; Ulmert, D.; Hugosson, J.; Lilja, H. Influence of blood prostate specific antigen levels at age 60 on benefits and harms of prostate cancer screening: Population-based cohort study. BMJ 2014, 348, g2296. [CrossRef] [PubMed]

27. Fenton, J.J.; Weyrich, M.S.; Durbin, S.; Liu, Y.; Bang, H.; Melnikow, H. Prostate-specific antigen-based screening for prostate cancer: Evidence report and systematic review for the US Preventive Services Task Force. JAMA 2018, 319, 1914-1931. [CrossRef] [PubMed]

28. Krieger, J.N.; Lee, S.W.; Jeon, J.; Cheah, P.Y.; Liong, M.L.; Riley, D.E. Epidemiology of prostatitis. Int. J. Antimicrob. Agents 2008, 31 (Suppl. 1), S85-S90. [CrossRef]

29. Krieger, J.N.; Nyberg, L., Jr.; Nickel, J.C. NIH consensus definition and classification of prostatitis. JAMA 1999, $282,236-237$. [CrossRef] [PubMed]

30. Carver, B.S.; Bozeman, C.B.; Williams, B.J.; Venable, D.D. The prevalence of men with National Institutes of Health category IV prostatitis and association with serum prostate specific antigen. J. Urol. 2003, 169, 589-591. [CrossRef]

31. Kawakami, J.D.; Siemens, R.; Nickel, J.C. Prostatitis and prostate cancer: Implications for prostate cancer screening. Urology 2004, 64, 1075-1080. [CrossRef]

32. Kandirali, E.; Boran, C.; Serin, E.; Semercioz, A.; Metin, A. Association of extent and aggressiveness of inflammation with serum PSA levels and PSA density in asymptomatic patients. Urology 2007, 70, 743-747. [CrossRef]

33. Harrell, F.E.; Lee, K.L.; Matchar, D.B.; Reichert, T.A. Regression models for prognostic prediction: Advantages, problems, and suggested solutions. Cancer Treat. Rep. 1985, 69, 1071-1077.

34. Carter, H.B. Prostate cancers in men with low PSA levels-must we find them? N. Engl. J. Med. 2004, 350, 2292-2294. [CrossRef] [PubMed]

35. Bokhorst, L.P.; Zhu, X.; Bul, M.; Bangma, C.H.; Schröder, F.H.; Roobol, M.J. Positive predictive value of prostate biopsy indicated by prostate-specific-antigen-based prostate cancer screening: Trends over time in a European randomized trial. BJU Int. 2012, 110, 1654-1660. [CrossRef] [PubMed]

36. Ferraro, S.; Bussetti, M.; Incarbone, P.G.; Rossi, R.S.; Panteghini, M. Is pre-biopsy serum prostate specific antigen retesting always justified? A study of the influence of individual and analytical factors on decision making for biopsy referral. Clin. Chim. Acta 2021, 516, 77-82. [CrossRef] [PubMed]

37. Bell, K.J.; Del Mar, C.; Wright, G.; Dickinson, J.; Glasziou, P. Prevalence of incidental prostate cancer: A systematic review of autopsy studies. Int. J. Cancer 2015, 137, 1749-1757. [CrossRef]

38. Thompson, I.M.; Ankerst, D.; Chi, C.; Lucia, M.S.; Goodman, P.J.; Crowley, J.J.; Parnes, H.L.; Coltman, C.A. Operating characteristics of prostate-specific antigen in men with an initial PSA level of $3.0 \mathrm{ng} / \mathrm{mL}$ or lower. JAMA 2005, 294, 66-70. [CrossRef] [PubMed]

39. Ahmed, H.U.; El-Shater Bosaily, A.; Brown, L.C.; Gabe, R.; Kaplan, R.; Parmar, M.K.; Collaco-Moraes, Y.; Ward, K.; Hindley, R.G.; Freeman, A.; et al. Diagnostic accuracy of multi-parametric MRI and TRUS biopsy in prostate cancer (PROMIS): A paired validating confirmatory study. Lancet 2017, 389, 815-822. [CrossRef]

40. Carobene, A.; Guerra, E.; Locatelli, M.; Cucchiara, V.; Briganti, A.; Aarsand, A.K.; Coskun, A.; Díaz-Garzón, J.; Fernandez-Calle, P.; Røraas, T.; et al. Biological variation estimates for prostate specific antigen from the European Biological Variation Study; consequences for diagnosis and monitoring of prostate cancer. Clin. Chim. Acta 2018, 486, 185-191. [CrossRef]

41. Serretta, V.; Catanese, A.; Daricello, G.; Liotta, R.; Allegro, R.; Martorana, A.; Aragona, F.; Melloni, D. PSA reduction (after antibiotics) permits to avoid or postpone prostate biopsy in selected patients. Prostate Cancer Prostatic Dis. 2008, 11, 148-152. [CrossRef]

42. Mohler, J.L.; Antonarakis, E.S.; Armstrong, A.J.; D'Amico, A.V.; Davis, B.J.; Dorff, T.; Eastham, J.A.; Enke, C.A.; Farrington, T.A.; Higano, C.S.; et al. Prostate cancer, version 2.2019, NCCN Clinical Practice Guidelines in Oncology. J. Natl. Compr. Cancer Netw. 2019, 17, 479-505. [CrossRef] [PubMed]

43. Epstein, J.I.; Zelefsky, M.; Sjoberg, D.D.; Nelson, J.B.; Egevad, L.; Magi-Galluzzi, C.; Vickers, A.J.; Parwani, A.V.; Reuter, V.E.; Fine, S.W.; et al. A contemporary prostate cancer grading system: A validated alternative to the Gleason score. Eur. Urol. 2016, 69, 428-447. [CrossRef] [PubMed]

44. Epstein, J.I.; Netto, G.J. Chapter 4 Inflammatory condition. In Biopsy Interpretation of the Prostate, 5th ed.; Lippincott Williams \& Wilkins: Philadelphia, PA, USA, 2015; pp. 25-26.

45. Brant, R. Inference for Means: Comparing Two Independent Samples. Available online: https://www.stat.ubc.ca/ \{\}rollin/stats/ ssize/n2.html (accessed on 29 April 2021). 
46. Heijnsdijk, E.A.M.; De Carvalho, T.M.; Auvinen, A.; Zappa, M.; Nelen, V.; Kwiatkowski, M.; Villers, A.; Páez, A.; Moss, S.M.; Tammela, T.L.J.; et al. Cost-effectiveness of prostate cancer screening: A simulation study based on ERSPC data. J. Natl. Cancer Inst. 2014, 107, 366. [CrossRef] [PubMed]

47. Eggener, S. Prostate cancer screening biomarkers: An emerging embarrassment of 'riches'? Eur. Urol. 2016, 70, 54-55. [CrossRef] [PubMed] 